\title{
CULTURAL HERITAGE MONUMENT DOCUMENTATION THROUGH ADAPTIVE PARAMETRIC DESIGN PROCESS
}

\author{
G. Tryfonos ${ }^{1 a^{*}}$, M. Ioannides ${ }^{1,2, b}$, A.G. Anastasi ${ }^{1 \mathrm{c}}$, V.A. Apostolou ${ }^{1 \mathrm{~d}}$, P.P. Pieri ${ }^{1 \mathrm{e}}$, M.A. Koundouris ${ }^{1 \mathrm{f}}$, F.G. Savva ${ }^{1 \mathrm{~g}}$ \\ ${ }^{1}$ UNESCO CHAIR on Digital Cultural Heritage, ${ }^{2}$ ERA Chair Mnemosyne, Department of Electrical Engineering and Information \\ Technology, Cyprus University of Technology, Arch. Kyprianou 31, 3036 Limassol, Cyprus \\ ( ${ }^{1 \mathrm{a}^{*}}$ george.tryfonos, ${ }^{1,2, \mathrm{~b}}$ marinos.ioannides)@cut.ac.cy ( ${ }^{1 \mathrm{c}}$ ang.anastasi, ${ }^{1 \mathrm{~d}}$ va.apostolou, ${ }^{1 \mathrm{e}}$ prp.pieri, ${ }^{1 \mathrm{f}}$ ma.koundouris, ${ }^{1 \mathrm{~g}}$ \\ fg.savva)@edu.cut.ac.cy
}

KEY WORDS: Parametric Design, cultural heritage, AEC for conservation, Building information modelling, 3D archiving, Virtual reality, Game Development, cloud archive.

\begin{abstract}
:
The paper presents a novel adaptive parametric documentation, modelling and sharing methodology, which aims to achieve a continuous holistic documentation, data processing and sharing process for cultural heritage community, such as architects, engineers, archaeologists, conservators, programmers, fabricators, contest creators, game developers, scholars and common citizens. Thus, the use of advance parametric and building information modelling software allows the processing and specification of all data by creating the 3D models needed for the multidisciplinary experts. Two Cypriot case studies from the medieval time period have been chosen for the development, and evaluation of our proposed methodology in order to investigate the process of modelling and sharing all the given metadata and 3D data. The first one is the Asinou Church, a UNESCO Heritage ${ }^{1}$ stone monument in the Troodos Mountains with a unique interior and the Kolossi Castle ${ }^{2}$, a former Crusader stronghold on the west of the city of Limassol on the island of Cyprus.
\end{abstract}

\section{INTRODUCTION}

The paper presents a novel adaptive parametric documentation, modelling and sharing methodology, which aims to achieve a continues holistic documentation, data processing and sharing process for cultural heritage multidisciplinary experts (Figure 1). Moreover, the ultimate goal is to create a continuous adaptive parametric data processing method for the documentation, modelling, reconstruction, preservation and presentation of cultural heritage monuments and sites.

Thus, the processing refers to four main stages:

- Mission planning and risk management assessment in preparation of data capture, including the metadata and paradata associated with the needs of different experts in the multidisciplinary community.

- Digitisation using terrestrial 3D laser scanners, UAV, material analysis and thermal photogrammetry along with the collection of historical data, using historical archives and subsequently enriching the metadata with the intangible heritage in a form of 'historical crowdsourcing' and indirect storytelling.

- 3D data pre- and post-processing by implementing an adaptive parametric modelling through visual programming data processing and data classification imported in building information modelling (BIM). This allows the control of the 3D geometric details and data management for the cultural heritage community and.

- A 3D data adaptation and optimisation for sharing the digital material in various formats according to the needs of the multidisciplinary experts.

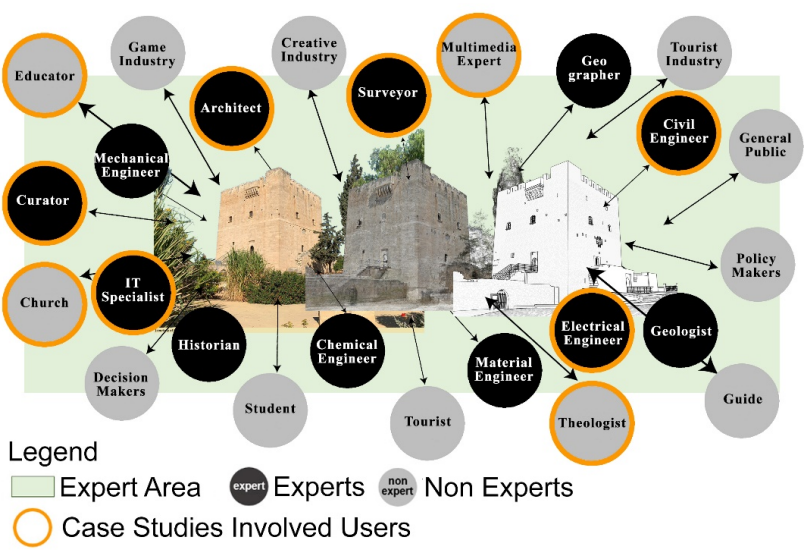

Figure 1. The diagram illustrates the multidisciplinary community of governmental organisations, research institutions and industrial professionals, which is needed for the holistic documentation in cultural heritage and/or the multidisciplinary community for the use and reuse of the content.

The use of data accusation devices such as laser scanning and photography allows to capture with accuracy the unique architectural details of cultural heritage (Yastikli, 2007) and to process them in $3 \mathrm{D}$ modelling software. Though parametric design software and by applying methodologies such as Heritage Building Information Modelling (H-BIM) (López et al., 2018), the aim is to provide architectural engineering and construction (AEC) data (Ioannides et al., 2016; Themistocleous et al., 2018). Those approaches allowing a continuous holistic building life cycle managing and monitoring of tangibles monuments data which can lead to the preservation from natural disasters.

\footnotetext{
* Corresponding author

${ }^{1}$ https://whc.unesco.org/en/list/351/

2 https://en.wikipedia.org/wiki/Kolossi_Castle
} 
Furthermore, by taking into account all the IPR issues and in order to promote and share the modelled content under open access, those data can be optimised, enriched and archived in repositories for $3 \mathrm{D}$ content The development of web-based cloud platforms, such us digital cultural heritage repository (Kounoudes, Artemi and Zervas, 2014) and 3D web-based presenters (Potenziani et al., 2015) allows the linked data to be harvested by aggregators for use and reuse (Isaac and Haslhofer, 2013). Important is to mention that the content can be used from experts in game development sector through mobile platforms and or AR-VR (Barazzetti and Banfi, 2017) to encourage education and cultural tourism.

Consequently, the need for various dataset, from experts and nonexperts (Figure 2) is a great challenge and requires continuous data optimisation for different file formats, software, presenters and platforms. Accordingly, the continuous adaptive parametric design process for documentation and modelling of complex heritage buildings is necessary. This will allow the data continues communication between a high level of accuracy for realistic representation and data simplification for AEC needs such as structural analysis and 2D line drawings.

This process requires in parallel, the use of BIM-based parametric design (Park, 2011) and advanced 3D modelling software allowing the continuous control of the 3D geometry and data. The collaboration and support of high-leading companies such as Autodesk (2021) and McNeel (2021) and the implementation of free open-source virtual programming and open-access plug-ins though one of the largest network in parametric design named Grasshopper (Rutten, 2021) allows easily unique modelling and data adaptation. This approach is been used for decades in the sector of architecture, engineering, automotive and construction allowing the generative $3 \mathrm{D}$ modelling, -simulation, continues 3D data monitoring and fabrication (Kontovourkis, Phocas and Tryfonos, 2013; Tryfonos, 2018). Thus, the implementation of such software in digital cultural heritage will allow to overpass the limitation of modelling accuracy and geometry control, allowing all the data that have been processed and modelled to be shared easily to the multidisciplinary community.

\section{METHODOLOGY FOR DOCUMENTATION THROUGH ADAPTIVE PARAMETRIC DESIGN PROCESS}

The proposed approach of adaptive parametric modelling aims to unlock the parallel workflow between multidisciplinary community. Following the lessons learned from very promising results in previous documentation and research works (Coughenour et al., 2015) (Figure 2), this paper focuses more on the digitisation and modelling with the use of a work-in-progress semi-automated parametric algorithm. Thus, the use of the Medieval Paphos Castle ${ }^{3}$ complex seaside wall is being used to explain the adaptive data processing from digitisation to H-BIM.

In order to evaluate and further develop our proposed methodology, two completed case studies from Cyprus Medieval monuments are being presented, which are dealing with the use of high detail and realistic data for creating an education game, as well as simplification, detail and AEC data such as drawings, analysis and 3D details to share them with the multidisciplinary experts through a cloud platform. The development of the game and the cloud platform are described below (Figure 3).

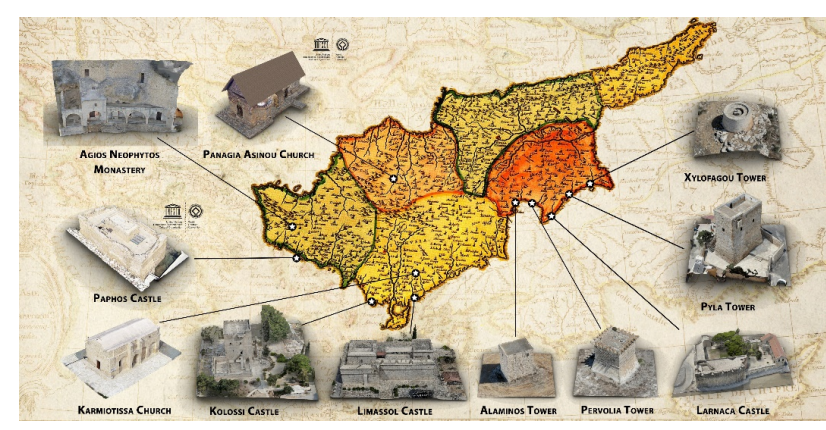

Figure 2. The UNESCO Chair on Digital Cultural Heritage at the Cyprus University of Technology documentation and modelling case studies. This map presents the location of Panagia Asinou and Karmiotissa Church, Agios Neophytos Monastery, Paphos, Kolossi, Limassol and Larnaca Castes and Alaminou, Pervolia, Pyla and Xylofagou Towers.

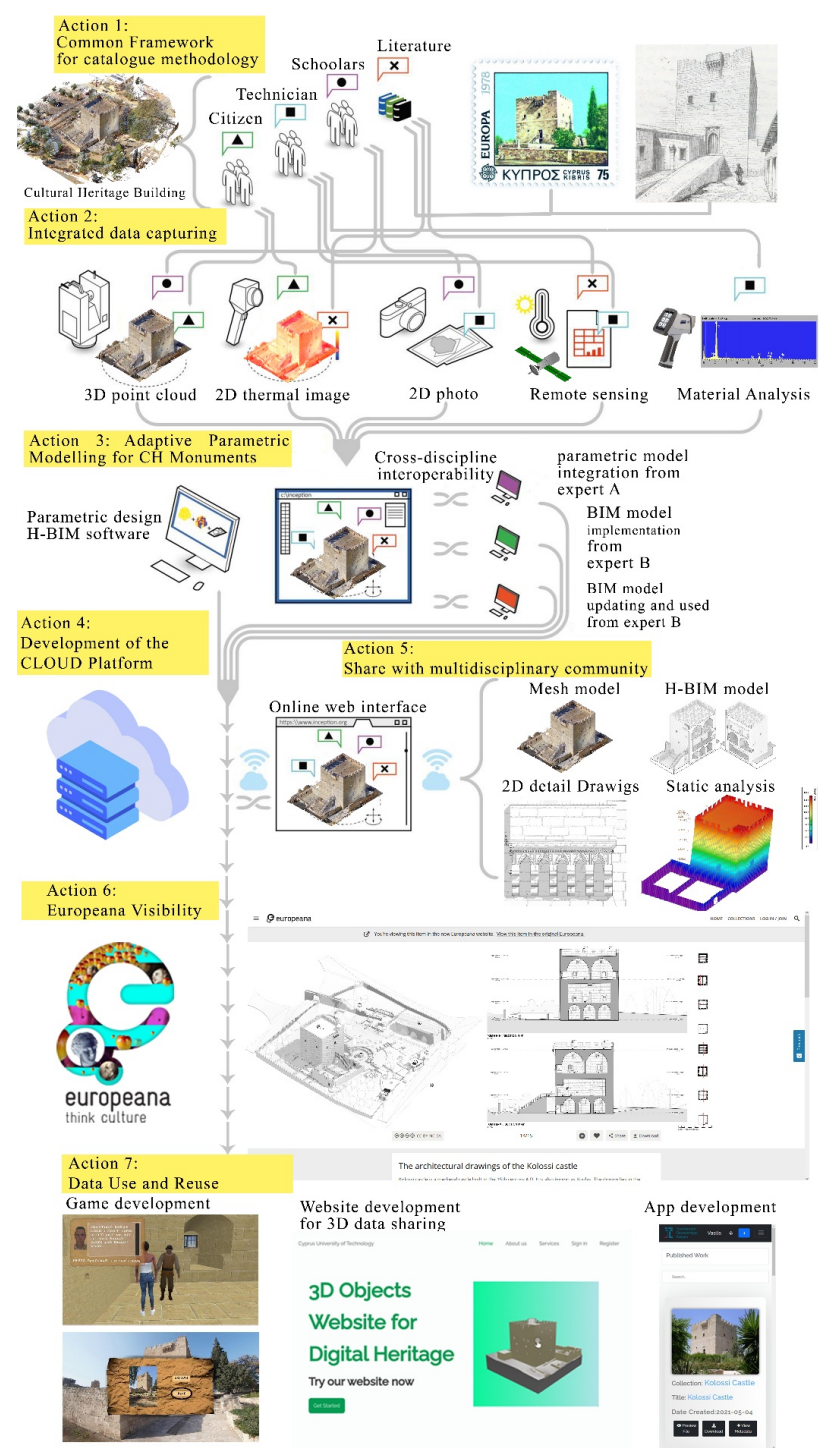

Figure 3. The methodology for the holistic documentation through adaptive parametric design process and the use of H-BIM for life cycle managing, monitoring and sharing.

\footnotetext{
${ }^{3}$ https://en.wikipedia.org/wiki/Paphos_Castle
} 


\subsection{Data acquisition and processing}

The processing of the big data acquired during the digitisation of the monuments determined not only an actual georeferenced 3D model but also metadata, information concerning the historical content, materials and texture of the monument such as the shape and size of the monument's stones in 3D at the given time of the data collection. The datasets are individual scans which have an overlapping of more than $85 \%$, which are then registered together. The data acquisition and post-processing results to the creation of a georeferenced single cloud of points repository which includes the metadata in the Cyprus Geodetic Reference System 1993, CGRS93 / Cyprus Local Transverse Mercator (LTM) (EPSG::6312). Briefly, to ensure the registered point cloud is georeferenced, a sufficient amount of ground control points (GCP) and control points (CP) were strategically placed around the archaeological site. The locations of the GCP and $\mathrm{CP}$ were determined during mission planning in the first stage of the methodology.

For example, the registration of Kolossi castle took 240 individual scan locations with a size of $\approx 800 \mathrm{MB}$ each around the archaeological site, resulting in a cloud of $3 \mathrm{D}$ points representing the exterior and interior of the monument. The uncertainty of the resulting point cloud was $\pm 3-4 \mathrm{~mm}$, this level of accuracy was set as a prerequisite due to the needs of the multidisciplinary experts involved in the mission planning stage of the methodology of this project and to ensure that the quality of the outcome would be at a sufficient level, in order to secure and archive the digitised monument (Figure 4).

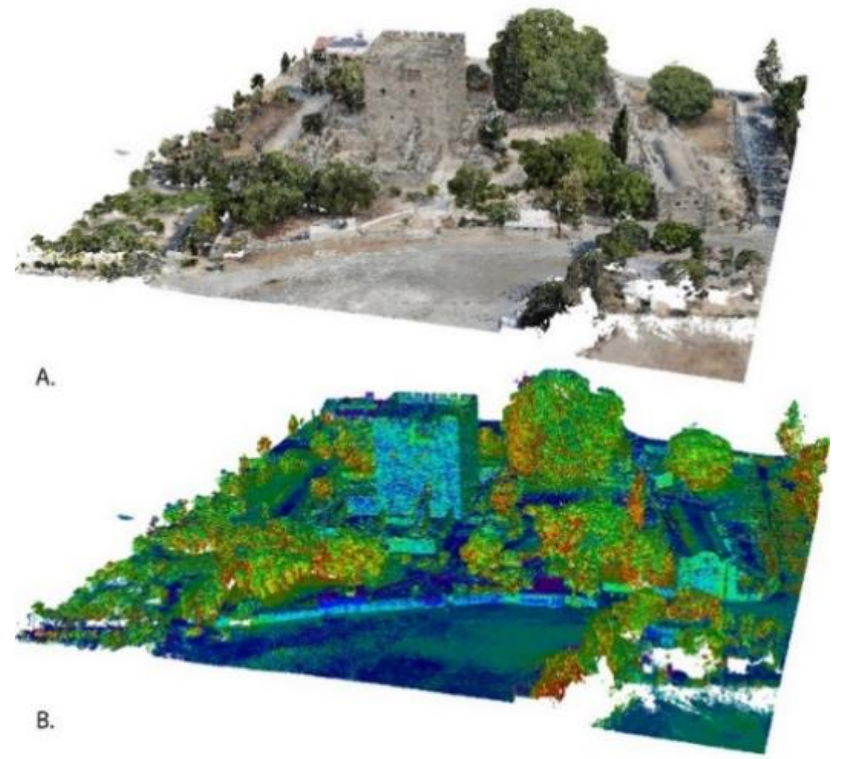

Figure 4. Kolossi pointcloud registered. A. Pointcloud with true RGB colour and B. Pointcloud displayed by intensity for i.e material documentation/specification.

In addition, an Aerial Photogrammetric method is used, with a Mavic 2 Enterprise (Zoom) (DJI, 2020) that is equipped with a FC2403 camera with a resolution of 12.71 Megapixel (4056x3040 4K), 1/2.3" CMOS and 82.6 ${ }^{\circ}(24 \mathrm{~mm})$ field of view. The image captures for Kolossi Castle reached a total of 2892 images. The photogrammetry process includes vertical images captured with a $50 \%$ side lap of the archaeological site from $\approx 32$ $\mathrm{m}$ attitude and the exterior of the main building from two (2) meters distance from the horizontal and vertical surfaces with an overlap of more than $80 \%$. In addition, the architectural details have been captured with a DSLR NIKKON 400D and reached a total of 1421 , with a resolution of 10.1 Megapixels $(3888 \times 2592$ $4 \mathrm{~K})$. The images have been captured from a close range of $0.5-$ 1 meter with an overlap of $90 \%$. These details include openings, doors, stairs and heraldic insignias.

Subsequently, all the datasets are be imported in Agisoft Metashape software (Agisoft, 2020). This process includes all images with high accuracy alignment in eight (8) clusters to optimize the software performance. High-quality mesh modelling with texture is been processed allowing the development of high quality orthophotos of $2 \mathrm{~mm} /$ pixel that can be used for 3D texture mapping in the parametric modelling stage.

\subsection{D data processing in H-BIM through adaptive parametric design modelling}

The results of the pointclouds from both laser scanning and photogrammetric processes are being merged in Agisoft Metashape (Agisoft, 2021) and exported as a point cloud for Autodesk Recap 2021 (Autodesk, 2021a) and as a textured mesh model for the Rhinoceros 3D (McNeel, 2021) for parametric modelling. The merged point cloud was converted in *.rcp file format supported by Recap and Revit with, $5 \mathrm{~mm}$ space grid unification. This setting allowed a smooth navigation using Autodesk Revit 2021 (Autodesk, 2021b) for the modelling of BIM elements. In addition, the use of Rhino.inside.Revit plug-in for Revit 2021 (Robert McNeel \& Associates, 2021) allowed us to fully integrate Rhinoceros 3D and Grasshopper with absolute tolerance of 0.001units (Rutten, 2021) to Revit.

In addition, the use of the suggested parallel semi-automated modelling workflow achieves the continues control of the mesh to solid geometry, where all the architectural elements results can be specified in Historical and non-Historical categories. In this way, the enrichment of metadata derived from historical archives can be achieved. Therefore, simple architecture elements such as door, floor, wall and windows can be modelled direct in Revit with all the functionalities and data. In case of high complexity free-form geometry, where Revit (Figure 6) functionality cannot be used for accurate modelling representation, the adaptive parametric algorithm is been applied. (Figure 7).

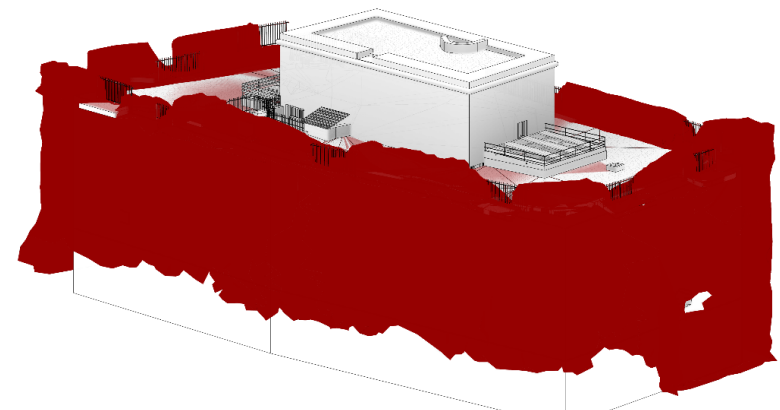

Figure 6. Paphos Castle seaside wall in Revit model elements linked with the Rhinoceros geometry in red colour. 


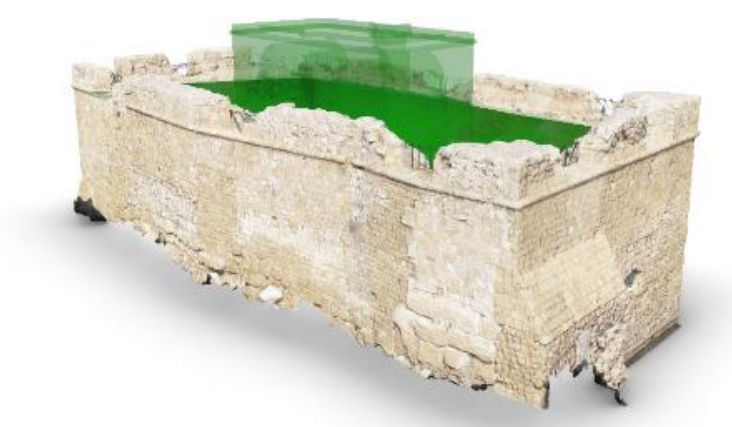

Figure 7. Paphos Castle seaside wall textured mesh in Rhinoceros software linked with the 3D Revit elements with green colour.

Furthermore, the raw mesh or 3D point cloud from Agisoft Metashape is specified in architecture categories and types such as wall "material" TypeN1 and wall "material" TypeN2, parapets" material" TypeN, windows"material"TypeN and doors"material"TypeN (N="hosted level" "Mark") allowing to study the morphologies and the materiality of the monument. Then is converted to quad mesh, achieving the smooth generation of the SudD surface. The smooth factor parameters control the target quad faces by reducing the initial mesh faces number, which archives the accuracy relation between points derived from laser scanning and or photogrammetry and NURBS solids (polysurfaces). Thus, the NURBS geometry allows us to project the 2D line drawings of the materials at the surface, add object related data such as material and geometry, as well as historical parameters to be at the same time integrated in the H-BIM model. Since all the process is done on the grasshopper parametric plugin, the row 3D point clouds can be directly linked to the modelling results and allows the geometry to adapt in the needed detail of the multidisciplinary experts.

Therefore, for the H-BIM model the smooth parameters are been set to $95 \%$, providing the needed $2 \mathrm{D}$ and $3 \mathrm{D}$ AEC data and drawings at scale 1:100. This is done in order to understand the geometric shape and the construction techniques and to monitor any construction progress or any changes caused by the environmental changes. Also, it simplifies the geometry, minimizing the model size. In case of the requirement of higher modelling detail at 1:1 scale of specific elements for CNC fabrication and assembly, such as heraldic insignias, those can be transferred in lower smooth factor minimizing the PTN or export directly from Rhinoceros 3D in a CNC language such as G-code. The proposed parametric algorithm aims the long-term preservation and adaptation of the data for the needs of the multidisciplinary experts (Figure 8).

In figure 8 we present the comparison of the $3 \mathrm{D}$ scan to H-BIM process of the suggested parametric algorithm and a standard approach manual modelling in Revit at one part of the Paphos castle's seaside wall. The results show that the standard manual modelling process can achieve a $15.6 \mathrm{~mm}$ accuracy (Figure 9.A) and the suggested automated process $3.1 \mathrm{~mm}$ accuracy (Figure 9.B). In addition, the standard approach results to a higher processing time for modelling accompanied by a high number of modelling edges.

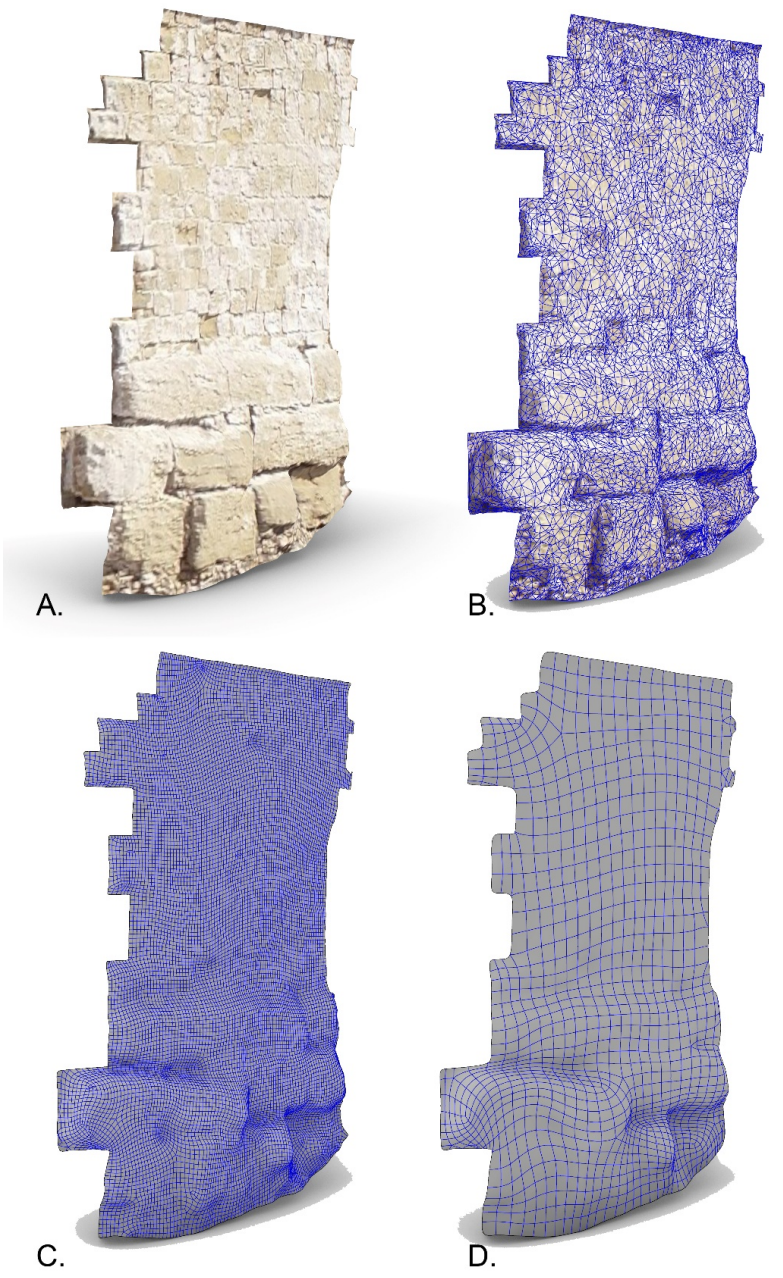

Figure 8. Paphos Castle seaside wall that shows two wall types. A. Demonstrates the result of the realistic mesh with the texture, B. The mesh wires that are been calculated at $12148, C$. The quad Sub-D surface of 12148 wires at $0 \%$ PTN with $0,771 \mathrm{~mm}$ accuracy that can be used for CNC fabrication, D. The quad Sub-D surface of 607 wires at $95 \%$ PTN with $3.1 \mathrm{~mm}$ accuracy that can be used to H-BIM for architecture and monitoring drawings, details and schedules.
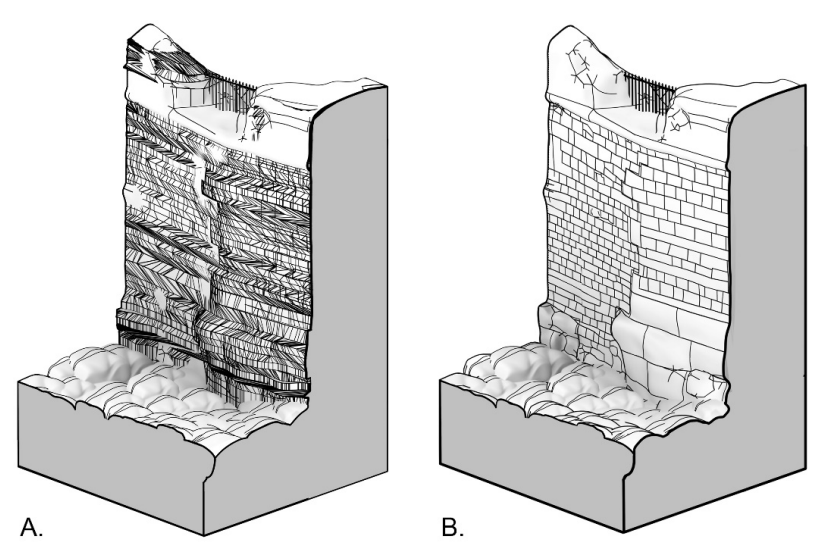

Figure 9. Part of the seaside wall that shows A. The results of standard modelling process using only Revit, B. The results of the suggested adaptive parametric algorithm.

The suggested adaptive parametric process allows the link and corelation of data such as, 3D point clouds, realistic mesh 
surfaces, drawings, details and schedules, as well as the transfer of the data with the multidisciplinary community. The H-BIM is a useful tool to understand the 3D morphologic geometry and the construction techniques. A data pull that is created and is linked to the $3 \mathrm{D}$ geometry can provide the life-cycle monitoring and managing of the monuments. Additionally, the metadata of the model can be easily enriched by the produced 3D holistic model (interior and exterior) of the castles as well as of the entire intangible story of the site allowing for the dynamic enrichment of the metadata to the digital model (Figure 10).

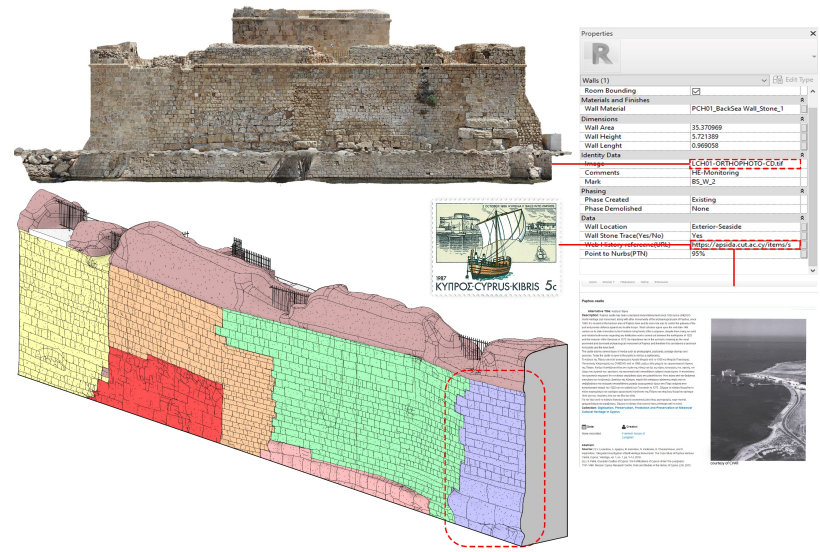

Figure 10. The seaside wall that is been generated using the suggested adaptive algorithm linked with the related data such as orthophotos, geometry characteristics and web archives.

\section{FURTHER DEVELOPMENT THROUGH TWO CASE STUDIES}

This approach aims to link the digitisation and modelling data and workflows between multidisciplinary community. In order to further develop the adaptive parametric algorithm, two case studies from Cyprus Medieval monuments have been chosen. The Asinou Church, an UNESCO Heritage stone monument in Troodos Mountains with a unique interior and 12th-century Byzantine paintings, and the Kolossi Castle, a former Crusader stronghold on the west of the city of Limassol. The main goal of those case studies is to investigate the process of sharing all the given parametric design process $3 \mathrm{D}$ data and metadata.

\subsection{Realistic representation of Asinou Church in 3D video game environment.}

The first case study of three graduate students thesis, aims to create an educational game in a realistic environment which audience above 12 years old could have fun playing and learning about the unique history of Panagia Asinou Church. The main goal is to allow the gamers to learn about the monument's tangible and intangible cultural heritage by navigating in first or third-person view inside and outside of the moments. Thus, the riddle approach has been used to introduce the player to the environment and common knowledge by providing essential directions, which the results are providing historical information related to the monuments and the site.

Therefore, a high-quality realistic model is required. Thus, the use of the adaptive parametric methodologies is been used to merge the high-quality mesh and texture of the exterior environment and interior frescoes of the church. Additionally, to improve the realistic experience of the gamer, the use of H-BIM categories such as doors, windows, roofs and floor are merged to Rhinoceros 3D, creating a complete $3 \mathrm{D}$ model of the monument.
(Figure 11). Then, the model is exported to Autodesk FBX Technology format (Buyuksalih et al., 2017) and imported to Unity (Unity Technologies, 2021). This approach allows the more realistic experience such as door opening, lighting though open windows and realistic sun lighting.

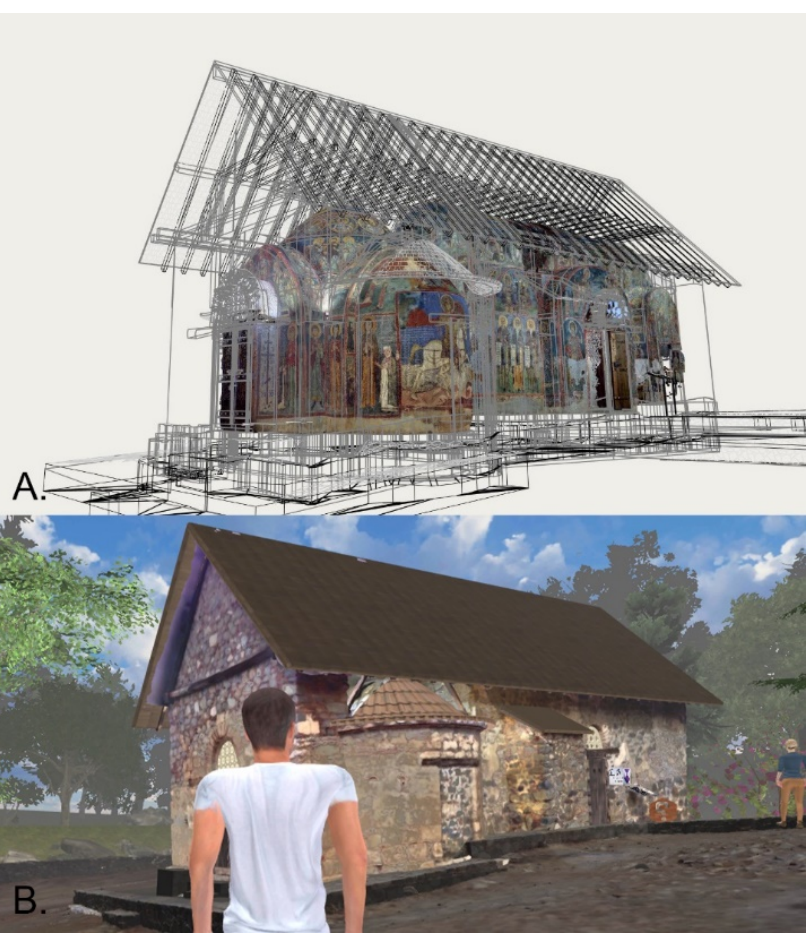

Figure 11. Asinou Church H-BIM and Unity model, A. the merged of the interior - frescoes mesh model and point cloud of the12th-century Byzantine paintings with the H-BIM inside Rhinoceros 3D through the adaptive parametric algorithm, B. The game environment with the $3 \mathrm{~d}$ textured mesh model merged with the H-BIM model.

The use of Unity C\# programming and the use of registerUser.php script within a database allows the creation of the online game "Solving History". The realistic 3D model is been enriched with historical data and archives that can be found at Apsida digital archives (Apsida, 2021b). Therefore, the use of the database and the data enriching of the metadata with the intangible heritage in a form of indirect storytelling through the riddles (Figure 12) and the game tour guides (Figure 13) through the non-player characters (NPC) allowing the gamer a realistic experience. Consequently, the experience and the rewards (Figure 14) that are been earned through the gamming, archives an indirect education of the nonexperts communities and promotes the Cyprus cultural heritage.

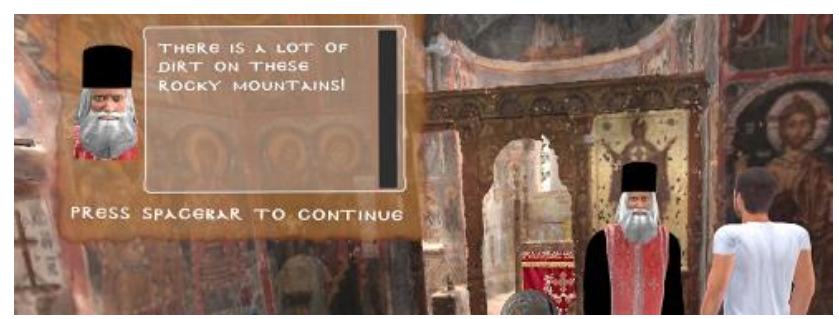

Figure 12. The game environment with Asinou Church presented, A. The riddle introduction inside the interior of the church though the NPC. 


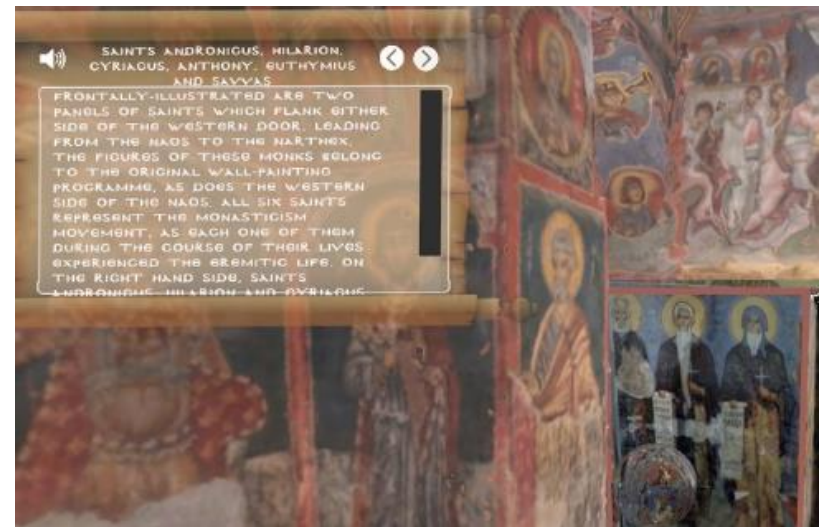

Figure 13. Tour guide through the frescoes with all the storytelling about the the12th-century Byzantine paintings.

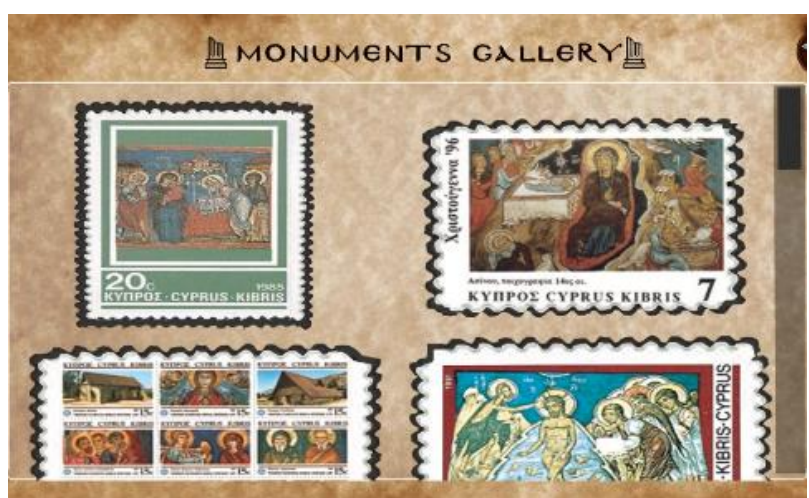

Figure 14. The gallery rewards related with the monument such as stamps (Apsida, 2021a).

\subsection{D cloud platform for the Kolossi Castle}

The second case study aims to create an online cloud platform for hosting online 3D cultural heritage objects. The ultimate objective was to integrate the $3 \mathrm{D}$ data and link them to all the related metadata and archives, allowing the use of the proposed platform for managing the monument and sides by the multidisciplinary experts such as archaeologists', conservators, architects, and engineers.

The online platform allows the visualisation of 3D objects and the enrichment of their corresponding metadata with information related to intangible data, which is available on online archives. Annotations are used to highlight detail in historical as well as geometrical content of the object, creating individual "records" Each record contains an uploaded Graphics Language Transmission Format (.glTF) (Khronos Group, 2021) representation, along with its corresponding metadata (Figure 14).. Additionally, each record allows to store data such as HBIM model files, FBX mesh files, 2D drawings in DWG or PDF file format, web links from online archives and texture or orthophoto image in jpg format (Figure 15). All the data can be published and shared with the multidisciplinary users for use and reuse.

In this case study, the Kolossi Castle, is used. The published $3 \mathrm{~d}$ of the castle is displayed in gITF and glb formats along with the annotation, metadata and shared file formats, allowing the navigation through 3D plans, drawings and details of the monument. The file preparation is done with the use of the suggested adaptive algorithm, allows the link of the H-BIM model to Rhinoceros and the exporting of the gITF or glb and FBX file format. Also the use of $3 \mathrm{~d}$ detail in H-BIM such as doors, emblems and windows follow the same process. Additionally, for the $2 \mathrm{~d}$ drawing files such as pdf or dwg each detail is exported directly from H-BIM model.

This process allows a smooth representation of Kolossi Castle 3D architecture elements in the cloud platform, linked with all the metadata and enriched with all the intangible data through online archives. All the above can be published and shared for the use and reuse from the multidisciplinary users. Hence, the proposed platform achieves the data sharing improving the area of cultural heritage management (Figure 16).
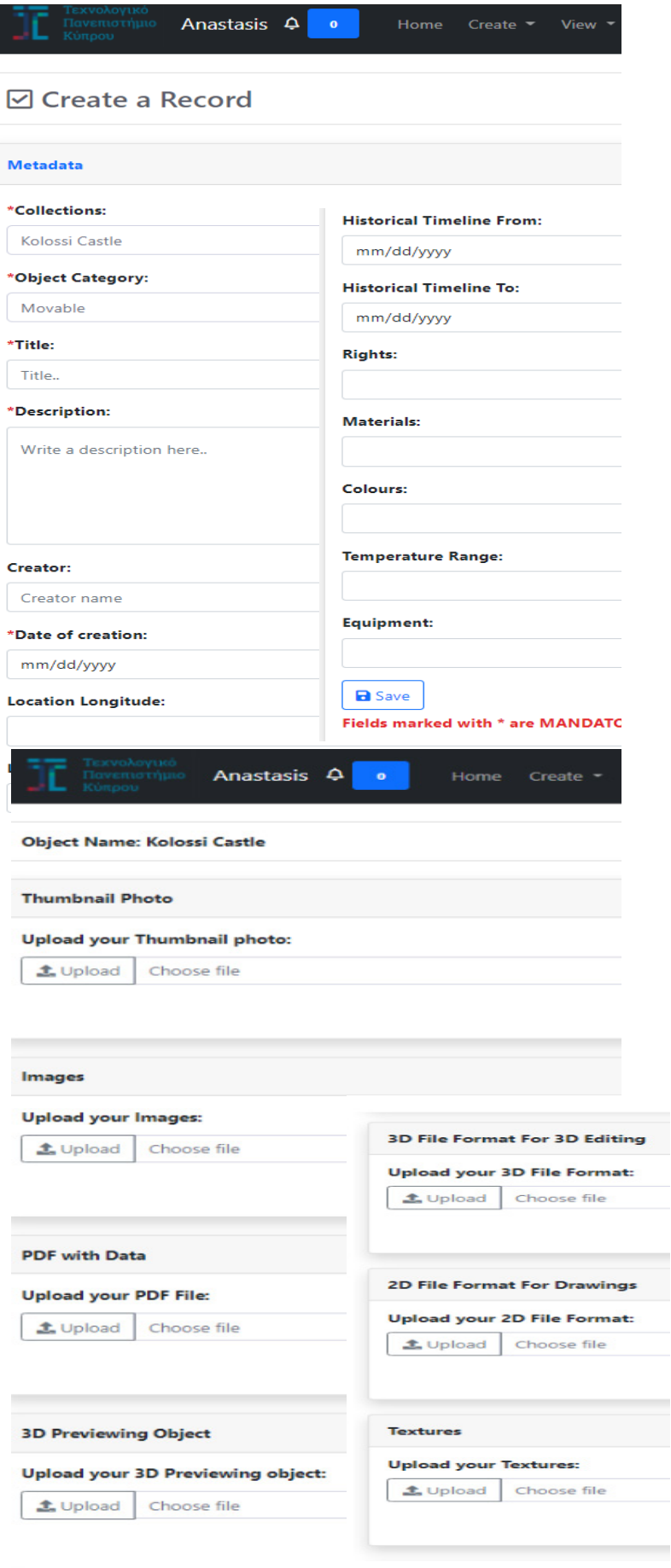

Figure 15. The setup of the annotations for the enrichment of metadata and the data that can be uploaded and shared. 


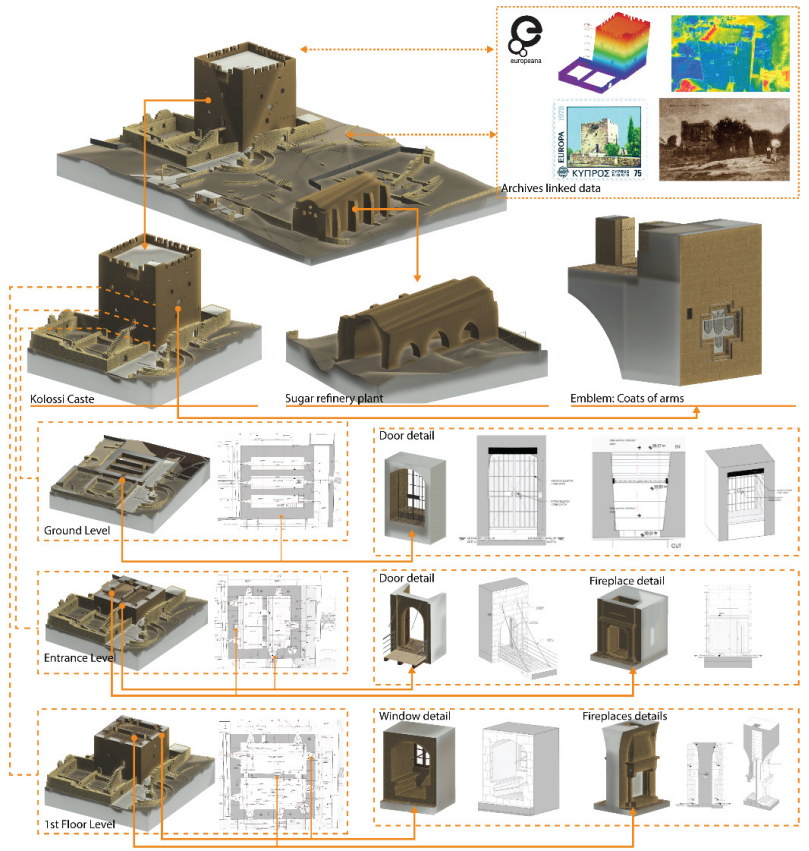

Figure 16. Kolossi Caste Collection sample map shows the gITF previews along with $2 \mathrm{D}$ drawings and details and linked with online archives data such as images, stamps, static analysis data, point clouds and thermal images.

\section{CONCUSSIONS}

This first attempt of the adaptive parametric design algorithm of high detail and accurate documentation in Cyprus case studies requires evaluation in order to follow the needs of the multidisciplinary community. This will achieve a continues workflow for the life-circle management for the long-term preservation of the monuments and sides. The suggested workflow aims to minimize the time needed for complex model optimisation and maximize the accuracy of data transfers for the needed data use. Through the case studies of Panagia Asinou church and Kolossi Castle, the innovation of the given technologies related to hardware and software is shown. This allows the demonstration of the adaptive parametric 3D data link that can be used along with the intangible heritage information. The two case studies that are derived from different industries are assessing the suggested methodology to adapt in the requested data. The successful realistic game experience and the online cloud 3D platform for AEC data sharing, shows the potential innovative aspect of the parametric modelling algorithms to handle the given big-data from digitisation.

Furthermore, the accuracy and detail in digitisation and modelling are fundamental steps for addressing the structural condition and preserve the monument. The data is processed and categorised through a semi-automated modelling method with accuracy - detail control. The use of parametric design algorithm in H-BIM systems by a detailed point cloud of the interior and exterior of the monument shows the novelty implementation of data modelling in complex shapes in digital cultural heritage. Further development can be done to optimise the data transferring and linking through online archives for the ultimate goal of a holistic parametric approach. This requires the continues assessment of the proposed algorithm through the use and reuse of the processing data.
This breakthrough parametric approach achieves the continues 3D model adaptation, allowing an end-less holistic documentation and monitoring of cultural heritage. Thus, the proposed methodologies generate a 3D H-BIM parametric model The H-BIM results can produce a holistic 3D model of the interior and exterior of the monuments as well as of the entire story of the site allowing the dynamic enrichment of the metadata to the digital model. All the data available can be adapted in such a way that it could be used by the multidisciplinary community and the creative industry.

\section{ACKNOWLEDGEMENTS}

The Kolossi and Paphos Castles documentation work was supported by «Interreg "DigiArc" - The Digitization, Preservation, Protection and Presentation of Medieval Cultural heritage in the island region of the Aegean and Cyprus» and it is co-funded up to $85 \%$ by the European Regional Development Fund and up to $15 \%$ by national resources of Greece and Cyprus, under the framework of Interreg VA Greece Cyprus Programme 2014-2020 approved by the European Commission on 27/07/2015 by decision CCI2014TC16RFCB055.

\section{REFERENCES}

Agisoft (2021) Agisoft Metashape. Available at: https://www.agisoft.com/.

Apsida (2021a) Birth of Christ. Available at: https://apsida.cut.ac.cy/items/show $/ 13668 \#$ ? $=\& m=\& \mathrm{~s}=\& \mathrm{cv}=\&$ $\mathrm{xywh}=-23 \% 2 \mathrm{C}-75 \% 2 \mathrm{C} 763 \% 2 \mathrm{C} 721$.

Apsida (2021b) Church of Panagia of Asinou Collection. Available at: https://apsida.cut.ac.cy/collections/show/102.

Autodesk (2021a) ReCap. Available at: https://www.autodesk.com/products/recap/overview.

Autodesk (2021b) Revit 2021. Available at: https://www.autodesk.com/products/revit.

Barazzetti, L. and Banfi, F. (2017) 'Historic BIM for Mobile VR/AR Applications BT - Mixed Reality and Gamification for Cultural Heritage', in Ioannides, M., Magnenat-Thalmann, N., and Papagiannakis, G. (eds). Cham: Springer International Publishing, pp. 271-290. doi: 10.1007/978-3-319-49607-8_10.

Buyuksalih, I. et al. (2017) '3D modelling and visualization based on the unity game engine--advantages and challenges.', in ISPRS Annals of Photogrammetry, Remote Sensing \& Spatial Information Sciences. Safranbolu, Karabuk, Turkey, pp. 161166

Coughenour, C. et al. (2015) 'Embedding Knowledge in 3D Data Frameworks in Cultural Heritage', ISPRS Annals of Photogrammetry, Remote Sensing and Spatial Information Sciences, II-5/W3, pp. 47-52. doi: 10.5194/isprsannals-II-5-W347-2015.

DJI (2020) Mavic 2 Enterprise (Zoom),. Available at: https://www.dji.com/mavic-2-enterprise/specs.

Ioannides, M. et al. (2016) 'Towards Monuments' Holistic Digital Documentation: the Saint Neophytos Enkleistriotis Case Study', in Ioannides, M. et al. (eds) Digital Heritage. Progress in Cultural Heritage: Documentation, Preservation, and 
Protection. Cham: Springer International Publishing, pp. 442473.

Isaac, A. and Haslhofer, B. (2013) 'Europeana Linked Open Data - data.europeana.eu', Semantic Web. IOS Press, 4, pp. 291-297. doi: $10.3233 / \mathrm{SW}-120092$.

Khronos Group (2021) glTF. Available at: https:/www.khronos.org/gltf/.

Kontovourkis, O., Phocas, M. and Tryfonos, G. (2013) 'Prototyping of an adaptive structure based on physical conditions', International Journal of Architectural Computing, 11(2). doi: 10.1260/1478-0771.11.2.205.

Kounoudes, A. D., Artemi, P. and Zervas, M. (2014) 'Apsida, Developing a Digital Cultural Heritage Repository', in Ioannides, M. et al. (eds) 5th International Conference, EuroMed 2014, Digital Heritage. Progress in Cultural Heritage: Documentation, Preservation, and Protection. Limasssol: Springer, pp. 259-265.

López, F. J. et al. (2018) 'A Review of Heritage Building Information Modeling (H-BIM)', Multimodal Technologies and Interaction, 2(2). doi: 10.3390/mti2020021.

McNeel, R. (2021) 'Rhinoceros'. Available at: https://www.rhino3d.com.

Park, J. (2011) 'BIM-Based Parametric Design Methodology for Modernized Korean Traditional Buildings', Journal of Asian Architecture and Building Engineering. Taylor \& Francis, 10(2), pp. 327-334. doi: 10.3130/jaabe.10.327.

Potenziani, M. et al. (2015) '3DHOP: 3D Heritage Online Presenter', Computers \& Graphics, 52, pp. 129-141. doi: https://doi.org/10.1016/j.cag.2015.07.001.

Robert McNeel \& Associates (2021) Rhino.inside.Revit. Available https://www.rhino3d.com/inside/revit/beta/referenc.

Rutten, D. (2021) Grasshoper. Available at: https://www.grasshopper3d.com/.

Themistocleous, K. et al. (2018) 'The First Attend for a Holistic HBIM Documentation of UNESCO WHL Monument: The Case Study of Asinou Church in Cyprus', in Ioannides, M. et al. (eds) Digital Heritage. Progress in Cultural Heritage: Documentation, Preservation, and Protection. Cham: Springer International Publishing, pp. 408-414.

Tryfonos, G. (2018) 'Automated robotic toolpath generation of elastic mesh structure', ArchiDOCT, Intelligence, 6(1), pp. 6577.

Unity Technologies (2021) Unity. Available at: https://unity.com.

Yastikli, N. (2007) 'Documentation of cultural heritage using digital photogrammetry and laser scanning', Journal of Cultural Heritage, 8(4), pp. 423-427. doi: 10.1016/j.culher.2007.06.003. 